\title{
Timing-adjusted iron dosing enhances erythropoiesis-stimulating agent-induced erythropoiesis response and iron utilization
}

\author{
Tomoyuki Kawano ${ }^{1,2}$, Tadashi Kuji ${ }^{1,3}$, Tetsuya Fujikawa ${ }^{1,4^{*}}$, Eiko Ueda ${ }^{1}$, Midori Shino ${ }^{1}$, Satoshi Yamaguchi ${ }^{5}$,
} Toshimasa Ohnishi', Kouichi Tamura ${ }^{1}$, Nobuhito Hirawa ${ }^{1}$ and Yoshiyuki Toya ${ }^{1}$

\begin{abstract}
Background: We recently demonstrated, using an index of recently synthesized hemoglobin, reticulocyte hemoglobin (Ret-Hb), that iron administration remarkably improves hemoglobin ( $\mathrm{Hb}$ ) synthesis during the period of high activation of erythropoiesis induced by the administration of a continuous erythropoietin receptor activator (CERA). We aimed to investigate whether repetition of iron dosing sustains effective erythropoiesis and suppresses iron storage.
\end{abstract}

Methods: In a 3-month comparison of monthly CERA administration, 104 hemodialysis patients were randomized into two groups that received $40 \mathrm{mg}$ iron intravenously 3 times; the first-week iron group [ $n=51]$, given iron in the first week after CERA administration, during the period of high activation of erythropoiesis, and the third-week iron group [ $n=53]$, given iron in the third week at the time of mild erythropoiesis activation.

Results: Initial mean CERA dosages were $123.5 \pm 67.5 \mu \mathrm{g} / \mathrm{month}$ and did not differ between the groups. Hb levels were not different between the groups throughout the study. One-week increases in Ret-Hb levels after CERA administration were higher, during the first and the third month, in the group given iron in the first week compared with the third-week iron group $(241.9 \pm 63.3$ vs. $196.2 \pm 82.8 \mathrm{mg} / \mathrm{dL}, P=0.004 ; 227.2 \pm 83.5$ vs. $187.9 \pm 88.7 \mathrm{mg} / \mathrm{dL}$, $P=0.037$, respectively). The increase in ferritin levels was suppressed 3 months later in the first-week iron group compared with that of the third-week iron group $(22.3 \pm 64.0$ vs. $69.0 \pm 76.6 \mathrm{ng} / \mathrm{mL}, P=0.002)$. Hepcidin levels decreased 1 week after CERA administration in both groups and were not different between the groups.

Conclusions: Timing-adjusted iron administration increased the levels of recently produced $\mathrm{Hb}$ and iron utilization and suppressed the ferritin levels. The iron administration timing deserves consideration when optimizing the efficiency of erythropoiesis-stimulating agents in patients undergoing hemodialysis.

Trial registration: UMIN000016375. Registered 29 January 2015.

Keywords: Hemodialysis, Renal anemia, Iron supplementation method, Continuous erythropoietin receptor activator

\section{Background}

Anemia is a common comorbidity among patients with end-stage renal disease requiring dialysis therapy and is a major cause of morbidity and mortality among hemodialysis (HD) patients [1]. Recombinant human

\footnotetext{
* Correspondence: tftf@yokohama-cu.ac.jp

'Department of Medical Science and Cardiorenal Medicine, Yokohama City University Graduate School of Medicine and School of Medicine, Yokohama, Kanagawa, Japan

${ }^{4}$ Center for Health Service Sciences, Yokohama National University,

Yokohama, Kanagawa, Japan

Full list of author information is available at the end of the article
}

erythropoietin is an effective treatment agent for renal anemia. Although anemia can be effectively corrected by erythropoiesis-stimulating agents (ESA) [2], responses to ESA vary widely among individuals [3, 4]. ESA response is a clinically important issue because a hampered response per se and anemia are risk factors for morbidity and mortality [3, 4]. Many factors, including iron deficiency, inflammation, and malnutrition, are related to responsiveness to ESA [5]. In particular, iron deficiency is a major cause of resistance to ESA therapy [6]. 
Ferritin and transferrin saturation (TSAT) are commonly used in routine clinical practice as indicators of iron storage and iron availability. The appropriate range is described in the Kidney Disease: Improving Global Outcomes guidelines [7], European Best Practice Guidelines [8], and Japanese guidelines [9]. Excessive iron supplementation has toxic effects [10], and observational studies have linked higher iron doses with mortality [11]. Nevertheless, the recommended range of ferritin, a marker of iron storage in the body, differs among guidelines around the world.

Ferritin levels are decreased by iron utilization during erythropoiesis [12-14]. The rate of decline in ferritin depends on the degree of stimulation of erythropoiesis. In a previous study, using epoetin beta pegol or continuous erythropoietin receptor activator (CERA), we showed that ferritin and TSAT levels decrease remarkably, associated with the increase in ESA-stimulated erythropoiesis, with a maximal response at 1 week [13]. Iron deficiency disturbs the ESA response [6]. The results imply that iron may be deficient during the transient ferritin drop.

Reticulocyte hemoglobin (Ret-Hb) is a specific, shortterm indicator for recently synthesized hemoglobin $(\mathrm{Hb})$, which is a valid index for the erythropoiesis response as compared with the $\mathrm{Hb}$ level. The $\mathrm{Hb}$ level comprises pre-existing $\mathrm{Hb}$ that is affected by multiple factors over approximately 3 months prior to the measurement, equivalent to the life span of red blood cells, implying that the erythropoiesis response is difficult to evaluate accurately using this index. In a subsequent study that utilized Ret-Hb levels, we showed that iron administration during a period of high stimulation of erythropoiesis was associated with a decline in the ferritin level in the first week after CERA administration, as well as remarkably improved $\mathrm{Hb}$ synthesis, compared with iron administration during the third week after CERA administration, during a period of mild activation of erythropoiesis [14]. The timing of iron dosing can be an important factor to achieve the optimal erythropoiesis by ESA.

However, the potential advantage by repetition of the time-adjusted iron dosing during highly stimulated erythropoiesis is unknown. We aimed to investigate whether repeated iron administration further enhances erythropoiesis and iron utilization, leading to suppression of iron storage in the body.

\section{Methods}

\section{Participants}

Study patients were recruited from outpatients undergoing HD at the Kohsaikai Bunkojin Clinic and Kohsaikai Kamioooka Jinsei Clinic in Yokohama, Japan. Patients were included if they underwent HD for $>12$ weeks, received ESA treatment for $\geq 12$ weeks before recruitment, and had ferritin levels below $200 \mathrm{ng} / \mathrm{mL}$. Patient exclusion criteria included patients with congestive heart failure, uncontrolled hypertension (diastolic blood pressure above $110 \mathrm{mmHg}$ ), malignancy, that has undergone major surgery within the previous 6 months, with gastrointestinal bleeding, the need for erythrocyte transfusion in the 12 weeks prior to the study, with systemic inflammatory disease and/or C-reactive protein levels $>3 \mathrm{mg} / \mathrm{dL}$, or receiving oral iron therapy and/or iron containing phosphate binder. After assessment, 104 patients were eligible for enrollment in the study (Fig. 1). The procedures followed were in accordance with the Helsinki Declaration. The institutional review board of Yokohama City University and the local ethics committee approved the protocol. This study was registered in the UMIN Clinical Trials Registry (registration ID number UMIN000016375). All patients provided written informed consent before enrollment.

\section{Study protocol}

This was a randomized, controlled, parallel-group study of 3 months duration. The previous study was a 1-month study using a short-term indicator of $\mathrm{Hb}$ synthesis; therefore, longer study duration was desirable to confirm the significance of the acceleration of $\mathrm{Hb}$ by time-adjusted iron dosing. A centralized allocation method was used to randomize eligible patients to receive intravenous iron during the first week or the third week after monthly CERA administration. The activation of erythropoiesis is high during the first week and mild during the third week after CERA dosing $[13,14]$. After inclusion in the study, CERA was not administered for a period of at least 4 weeks and iron implementation was continued as needed at each clinic. At the start of the study, demographic, clinical, and laboratory data were recorded for each patient. CERA (Mircera ${ }^{\circ}$; Chugai Pharmaceutical Co., Tokyo, Japan) was administered monthly (days 0, 28,

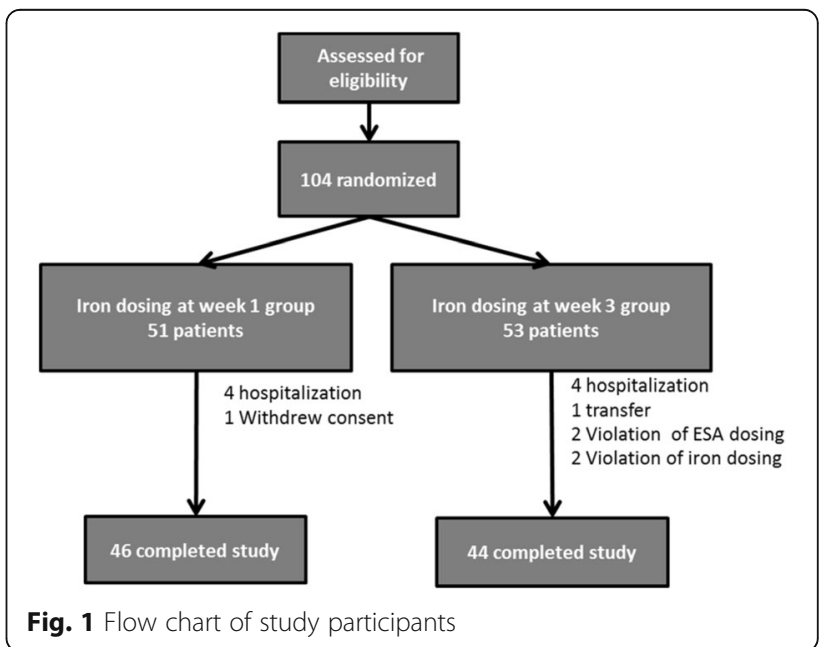


and 56) to maintain the target $\mathrm{Hb}$ level of $10-11 \mathrm{~g} / \mathrm{dL}$, according to the 2008 Guidelines for Renal Anemia in Chronic Kidney Disease of the Japanese Society for Dialysis Therapy [9]. CERA doses were adjusted as needed at the discretion of attending physicians. Each patient received $40 \mathrm{mg}$ intravenous elemental iron (Fesin'; Nichi-Iko Pharmaceutical Co., Ltd., Toyoma City, Japan) at all $3 \mathrm{HD}$ sessions during the first week after monthly CERA administration (days $0,2,4,28,30$, $32,56,58$, and 60 ; the first-week iron group; $n=51$ ) or at all 3 sessions during the third week after monthly CERA administration (days 14, 16, 18, 42, 44, 46, 70, 72, and 74; the third-week iron group; $n=53$ ). $\mathrm{Hb}$ and reticulocyte $\mathrm{Hb}$ equivalent (Ret-He) levels were examined immediately before and 1 week after the HD session at which CERA was administered (days $0,7,28,35,56,63$, and 84). TSAT and ferritin levels were examined before the HD session at which CERA was administered every 4 weeks (days 0,28 , 56 , and 84). During the first month, hepcidin, ferritin, and TSAT were evaluated weekly (days $0,7,14,21$, and 28). TSAT was calculated using the following formula: TSAT $(\%)=$ serum iron $(\mu \mathrm{g} / \mathrm{dL}) /$ total iron-binding capacity $(\mu \mathrm{g} /$ $\mathrm{dL}) \times 100$. HD was performed 3 times per week regularly for 3-6 h with a dialysate flow rate of $400 \mathrm{~mL} / \mathrm{min}$ in most patients, and the blood flow rate ranged from 150 to $280 \mathrm{~mL} / \mathrm{min}$. Dry weight was determined for each patient using the pre-dialysis cardiothoracic ratio. Before the study, intravenous doses of $40 \mathrm{mg}$ of elemental iron per week were administered if the serum ferritin level was below $100 \mathrm{ng} / \mathrm{mL}$ and transferrin saturation was less than $20 \%$.

\section{Analytical methods}

Ret-He shows the $\mathrm{Hb}$ amount per reticulocyte and has been proved to be a direct indicator of iron utilization as well as reticulocyte $\mathrm{Hb}$ content or $\mathrm{CHr}[15,16]$. Conventional erythrocyte parameters and Ret-He were measured using an XE-5000 hematology analyzer (XE RET MASTER; Sysmex, Kobe, Japan). Ret-He was analyzed using a fluorescent flow cytometry technique. In the reticulocyte channel, using a polymethine dye, this technique also determines the mean value of forward light scatter intensity derived from mature erythrocytes and reticulocytes [15]. The $\mathrm{Hb}$ concentration is a measure of the total amount of $\mathrm{Hb}$, including pre-synthesized $\mathrm{Hb}$, whereas the Ret-Hb concentration is a specific index of recently synthesized $\mathrm{Hb}$. The Ret-Hb level enables estimates to be made of the efficiency in erythropoiesis during the previous 3-4 days. Ret-Hb (mg/dL) was calculated by multiplying Ret-He (pg) per cell by the reticulocyte count $\left(10^{9}\right.$ cells $\left./ \mathrm{L}\right)$, as described previously $[14,17]$. CERA-induced erythropoiesis is the most highly activated in the first week after CERA administration $[13,14]$, and iron dosing enhances erythropoiesis efficiency, especially in the first week [14]. To assess the peak activation of erythropoiesis induced by CERA, the 1-week increase in Ret-Hb was applied, defined as the increase in Ret-Hb levels from day 0 to day 7 after CERA administration.

\section{Statistical analysis}

Sample size was estimated based on a previous report [14] with the following assumptions: $\alpha$ was set at 0.05 , the expected power was $80 \%$, a difference between groups in changes of ferritin of $17 \%$, and a standard deviation of $30 \%$. Unless otherwise specified, data are presented as mean \pm standard deviation. Differences between the groups were analyzed using the unpaired Student's $t$ test for parametric variables or the Wilcoxon sum rank test for non-parametric valuables, with the $\chi^{2}$ test used to determine proportions. $P$ values of $<0.05$ were considered to be statistically significant. Statistical analyses were performed using SPSS for Windows version 19.0 (SPSS, Inc., Chicago, IL, USA).

\section{Results}

Figure 1 displays a flow chart of the study patients. During the 3-month comparison period, 5 patients from the firstweek iron group withdrew from the study, owing to hospital admission $(n=4)$ and withdrawal of consent $(n=1)$. Nine patients in the third-week iron group withdrew because of hospital admission $(n=4)$, clinic transfer $(n=1)$, extra ESA administration $(n=2)$, and iron dosing violations $(n=2)$ (Fig. 1). The baseline characteristics of the 104 patients (the first-week iron group, $n=51$; the thirdweek iron group, $n=53$ ) are shown in Table 1 . No significant differences in baseline characteristics were evident between the groups.

Ninety participants (the first-week iron group, $n=46$; the third-week iron group, $n=44$ ) were included in the final analysis. No significant differences in baseline characteristics were detected between the groups included in the final analysis. Initial CERA dosages were 130.4 \pm $67.3 \mu \mathrm{g} / \mathrm{month}$ in the first-week iron group and $116.5 \pm$ $69.0 \mu \mathrm{g} /$ month in the third-week iron group $(P=0.334)$. There were no significant differences in the CERA dosages over the 3-month comparison period between the firstweek and third-week iron groups (1st month, $1.09 \pm$ $1.22 \mu \mathrm{g}$ vs. $2.84 \pm 24.8 \mu \mathrm{g}, P=0.637$; 2 nd month, $-9.78 \pm$ $31.4 \mu \mathrm{g}$ vs. $-5.11 \pm 42.7 \mu \mathrm{g}, P=0.413$; 3rd month, $-21.2 \pm$ $38.0 \mu \mathrm{g}$ vs. $-14.8 \pm 45.9 \mu \mathrm{g}, P=0.312$ ). The mean Hb levels during the 3 month comparison period were $10.1 \pm 0.8 \mathrm{~g} /$ $\mathrm{dL}$ in the first-week iron group and $10.2 \pm 0.7 \mathrm{~g} / \mathrm{dL}$ in the third-week iron group $(P=0.901)$. No patients required blood transfusion during the study period.

Changes in $\mathrm{Hb}$ levels, compared with baseline, Ret- $\mathrm{Hb}$ levels, TSAT, and ferritin levels are shown in Fig. 2. The increases seen in $\mathrm{Hb}$ levels at 1, 2, and 3 months were 
Table 1 Baseline characteristics of patients between first-week iron and third-week iron groups

\begin{tabular}{|c|c|c|c|}
\hline \multirow[t]{2}{*}{ Variables } & \multirow{2}{*}{$\begin{array}{l}\text { First-week iron group } \\
n=51\end{array}$} & \multirow{2}{*}{$\begin{array}{l}\text { Third-week iron group } \\
n=53\end{array}$} & \multirow[t]{2}{*}{$P$ value } \\
\hline & & & \\
\hline Age, years & $67.8 \pm 10.2$ & $67.6 \pm 11.6$ & 0.919 \\
\hline Male, \% & 60.8 & 52.8 & 0.413 \\
\hline Body mass index, kg/m2 & $21.9 \pm 3.6$ & $21.8 \pm 3.2$ & 0.815 \\
\hline Hemodialysis vintage, months & $94.7 \pm 89.0$ & $108.0 \pm 75.5$ & 0.158 \\
\hline Single-pool Kt $N$ & $1.05 \pm 0.20$ & $1.12 \pm 0.24$ & 0.113 \\
\hline Mean CERA dose, $\mu \mathrm{g} / 4$ weeks & $129.6 \pm 66.9$ & $117.9 \pm 68.2$ & 0.344 \\
\hline Arteriovenous fistula, \% & 96.1 & 98.1 & 0.465 \\
\hline Renin-angiotensin system inhibitors, \% & 49.0 & 58.5 & 0.333 \\
\hline Diabetes mellitus, \% & 35.3 & 41.5 & 0.515 \\
\hline Hypertension, \% & 96.1 & 98.1 & 0.485 \\
\hline Cardio vascular disease, \% & 25.5 & 24.5 & 0.910 \\
\hline Hematologic disease, \% & 5.9 & 1.9 & 0.294 \\
\hline Hemoglobin, g/dl & $10.7 \pm 0.7$ & $10.8 \pm 0.9$ & 0.767 \\
\hline Creatinin, mg/dl & $11.0 \pm 2.2$ & $1.0 \pm 2.5$ & 0.906 \\
\hline Blood urea nitrogen, mg/dl & $71.6 \pm 17.1$ & $72.3 \pm 14.6$ & 0.844 \\
\hline Albumin, g/dl & $3.85 \pm 0.22$ & $3.85 \pm 0.31$ & 0.969 \\
\hline C-reactive protein, mg/dl & $0.32 \pm 0.54$ & $0.22 \pm 0.34$ & 0.865 \\
\hline Intact-parathyroid hormon, pg/ml & $164.7 \pm 78.8$ & $180.1 \pm 108.2$ & 0.797 \\
\hline Serum iron, $\mu \mathrm{g} / \mathrm{dl}$ & $96.4 \pm 30.1$ & $89.6 \pm 25.9$ & 0.248 \\
\hline Total Iron binding capacity, $\mu \mathrm{g} / \mathrm{dl}$ & $236.7 \pm 34.1$ & $237.1 \pm 42.7$ & 0.955 \\
\hline Transferrin saturation, \% & $40.9 \pm 14.2$ & $40.2 \pm 14.8$ & 0.826 \\
\hline Ferritin, ng/ml & $163.3 \pm 63.7$ & $169.6 \pm 63.1$ & 0.623 \\
\hline
\end{tabular}

Data are mean \pm SD. $P$ values for the difference between the two groups

CERA continuous erythropoietin receptor activator

not significantly different between the groups (Fig. 2a). The 1-week increases in Ret-Hb levels after CERA administration were higher, during the first and the third month, in the group given iron in the first week compared with the third-week iron group $(241.9 \pm 63.3 \mathrm{mg} /$ dL vs. $196.2 \pm 82.8 \mathrm{mg} / \mathrm{dL}, P=0.004 ; 227.2 \pm 83.5 \mathrm{mg} / \mathrm{dL}$ vs. $187.9 \pm 88.7 \mathrm{mg} / \mathrm{dL}, P=0.037$; Fig. $2 \mathrm{~b}$ ). Changes in TSAT did not differ at 1,2 , and 3 months between the groups (Fig. 2c). The ferritin levels increased to a lesser degree in the first-week iron group at 1,2, and 3 months, compared with the third-week iron group $(-5.37 \pm 32.9$ vs. $37.1 \pm 46.6 \mathrm{ng} / \mathrm{mL}, P<0.001 ; 16.5 \pm 60.0$ vs. $56.4 \pm$ $56.9 \mathrm{ng} / \mathrm{mL}, P=0.002 ; 22.3 \pm 64.0$ vs. $69.0 \pm 76.6 \mathrm{ng} / \mathrm{mL}$, $P=0.002$, respectively; Fig. $2 \mathrm{~d}$ ).

Hepcidin and iron-related parameters were measured weekly during the first month. Hepcidin levels decreased at 1-week post-treatment in both groups, and changes in hepcidin levels were not significantly different between the groups (Fig. 3a). Changes in iron-related parameters from week 0 were evaluated in the same way as in the previous study [14]. Changes in TSAT levels were not different between the groups (Fig. 3b). At 1 and 2 weeks after CERA administration, the decreases seen in ferritin levels were not as pronounced in the first-week iron group compared with the third-week iron group (5.1 \pm 23.7 vs. $-59.2 \pm 23.9 \mathrm{ng} / \mathrm{mL}, P<0.001 ;-39.6 \pm 35.6$ vs. $-78.8 \pm 37.6 \mathrm{ng} / \mathrm{mL}, P<0.001$, respectively. Fig. 3c). The ferritin levels increased to a lesser degree at 3 and 4 weeks after CERA administration in the first-week iron group compared with the third-week iron group $(-26.1$ \pm 35.7 vs. $84.2 \pm 315.2 \mathrm{ng} / \mathrm{mL}, P=0.023 ;-5.4 \pm 32.9$ vs. $37.1 \pm 46.6 \mathrm{ng} / \mathrm{mL}, P<0.001$, respectively. Fig. $3 \mathrm{c})$.

\section{Discussion}

This study compared erythropoiesis efficiency and ironrelated parameters between two schedules of iron administration, during highly stimulated erythropoiesis and mildly stimulated erythropoiesis, and found an increase in $\mathrm{Hb}$ synthesis and inhibition of ferritin levels when iron was administered during highly stimulated erythropoiesis.

Ret- $\mathrm{Hb}$ is a reticulocyte-related marker that is a measure of recently generated $\mathrm{Hb}$. Iron administration during the activation of erythropoiesis leads to increased Ret$\mathrm{Hb}$ levels, and a benefit was observed from repeated iron 

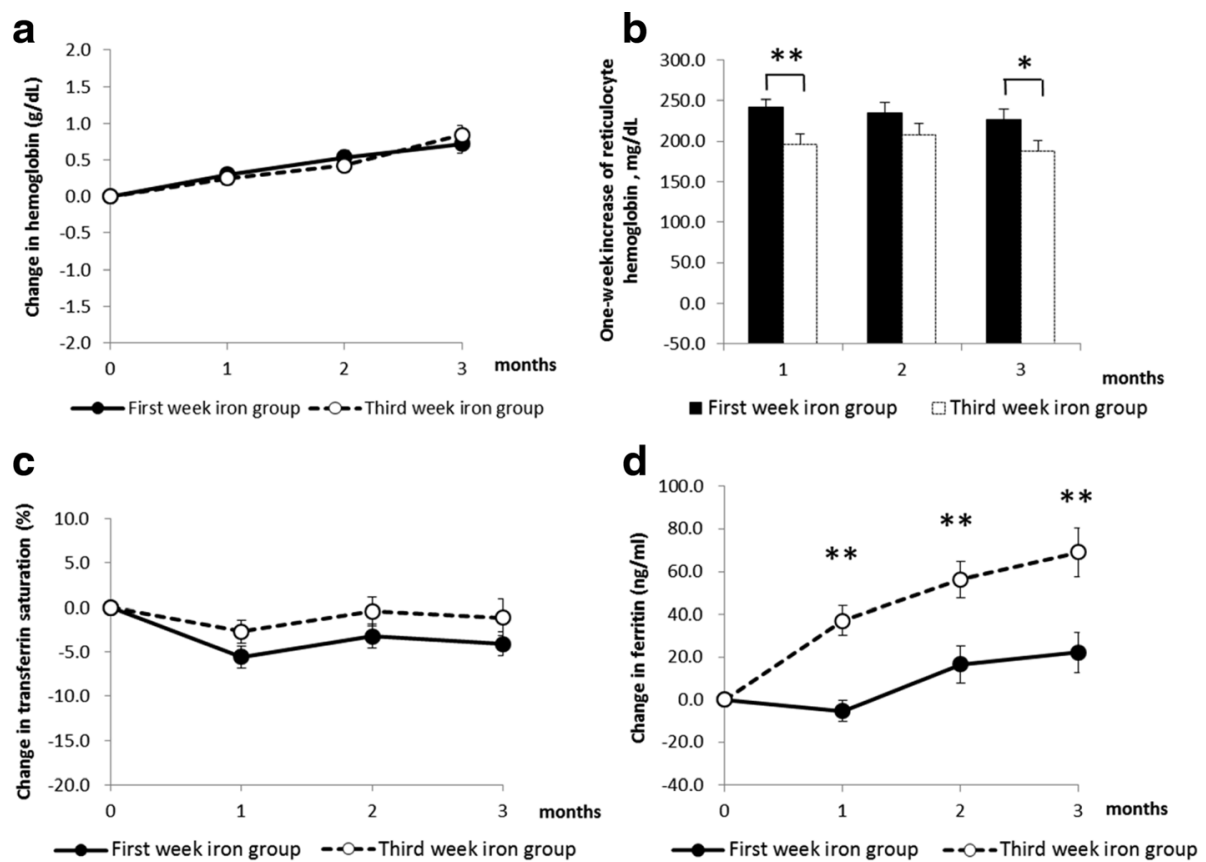

Fig. $\mathbf{2}$ Changes in a hemoglobin levels, $\mathbf{c}$ transferrin saturation, and $\mathbf{d}$ ferritin levels, and $\mathbf{b}$ 1-week increase in reticulocyte hemoglobin levels between groups that received iron administration in the first week or the third week following CERA administration. CERA was administered every month. Data are presented as means \pm standard error of mean. ${ }^{*} P<0.01,{ }^{* *} P<0.05$, for comparisons between the groups

administration on a monthly basis. The result has confirmed that the iron administration improves erythropoiesis efficiency by enhancing erythropoiesis. This suggests that iron should be administered according to the increase in iron requirement during erythropoiesis.

In this 3-month comparison, the increase in ferritin levels was not as large when iron was administered during the period of high stimulation of erythropoiesis, compared with administration during mild erythropoiesis stimulation. This is the first report to show a difference in the degree of ferritin induction, dependent on the timing of iron administration, in a study with a randomized controlled trial design. Our result suggests that iron administration during highly activated erythropoiesis enhances iron utilization and erythropoiesis, leading to inhibition of iron storage. It is worth examining whether an improvement in iron utilization maintains a low ferritin level and contributes to a favorable prognosis.

Intravenous iron dosing causes a transient excessive increase in serum non-transferrin-bound iron and evokes inflammation [18, 19]. Inflammation increases ferritin levels [20]. The increase in non-transferrin-bound iron may enhance the rise in ferritin levels after intravenous iron dosing. Iron administration during activated erythropoiesis increased newly produced $\mathrm{Hb}$. Enhanced iron utilization might have suppressed the increase in the peak level of the transient non-transferrin-bound iron. Further research is needed to investigate whether the transient increase in non-transferrin-bound iron is suppressed and whether the suppression is a key mechanism accounting for the difference in ferritin levels between the groups.

Intravenous iron causes a transient rapid increase in ferritin within 1 week, exceeding real storage [21]. Therefore, in this study, ferritin level was measured at least 10 days after iron dosing. Although ferritin levels were measured in the standard manner, long-term follow-up is needed to further confirm the suppression of ferritin levels after iron dosing during highly stimulated erythropoiesis and to assess body iron stores in patients with a suppressed ferritin level.

Iron dosing reportedly increases hepcidin levels [22]. In our study, iron was not administered at the same time but at different times in the two groups. This allowed us to compare the reactions of hepcidin during the presence and absence of iron dosing. However, our data did not show a difference in hepcidin levels, measured weekly, associated with iron dosing during the first week and the third week. Hepcidin levels decrease according to the iron requirement during activated erythropoiesis [13]. The effect of activated erythropoiesis on decreasing hepcidin levels might suppress the effect of iron administration in increasing hepcidin levels. Hepcidin is an important factor that hinders iron intake into reticulocytes [23]. It remains to be determined whether iron dosing during the activation of erythropoiesis can prevent a rise in hepcidin levels. 


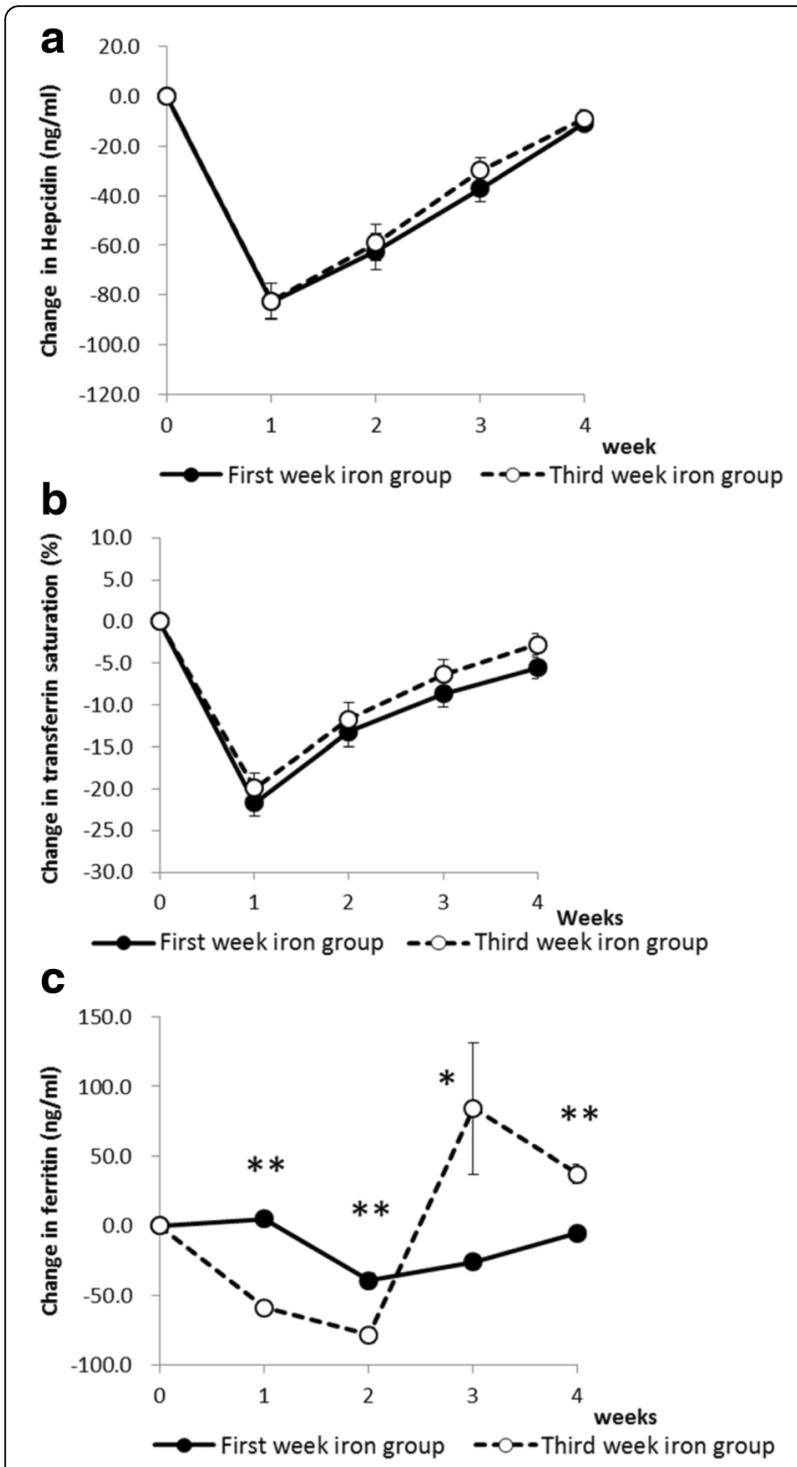

Fig. 3 Changes in a hepcidin levels, b transferrin saturation, and $\mathbf{c}$ ferritin levels between groups that received iron administration in the first week or the third week following CERA administration. CERA was administered on day 0 . Data are presented as means \pm standard error of mean. ${ }^{*} P<0.01,{ }^{*} P<0.05$, for comparison between the groups

There was no significant difference in $\mathrm{Hb}$ levels between the groups, probably because ESA dose adjustments were conducted appropriately to maintain target levels. The scale and duration of this study did not allow the detection of ESA dose differences between the groups. However, iron dosing during activated erythropoiesis increased the efficiency of erythropoiesis and suppressed iron storage. It is possible that the ESA dose required to maintain targeted $\mathrm{Hb}$ levels might be reduced by timing the administration of iron during activated erythropoiesis.

\section{Limitations}

There were limitations in this study. Firstly, the number of study participants was not adequate and a number of patients withdrew from the study; there is further scope to investigate the effect of timing-adjusted iron administration on the balance between ESA and $\mathrm{Hb}$ levels achieved. Secondly, the patient exclusion criteria had the potential to introduce a selection bias. This study did not include patients with baseline ferritin levels over $200 \mathrm{ng} / \mathrm{mL}$. The patients with high ESA resistance often have high ferritin levels and need more effective therapy for anemia. It is worth examining whether our results apply to these populations. Furthermore, the excluded patients with severe conditions may have a notable benefit from timing-adjusted iron administration methods. Further study is needed to examine the characteristics of patients that benefit the most from receiving timingadjusted iron administration. Thirdly, this study was not designed to investigate the optimal dose of iron supplementation during the activation of erythropoiesis. It is still necessary to elucidate what amount of iron supplementation, given with adjusted timing, is required during ESA therapy.

\section{Conclusions}

These results suggest that timing-adjusted iron administration leads to an increase in recently produced $\mathrm{Hb}$ and iron utilization and suppresses ferritin levels. Iron administration timing deserves consideration when optimizing ESA efficiency in HD patients.

\section{Abbreviations}

CERA: Continuous erythropoietin receptor activator; ESA: Erythropoiesisstimulating agents; Hb: Hemoglobin; HD: Hemodialysis; Ret-Hb: Reticulocyte hemoglobin; Ret-He: Reticulocyte hemoglobin equivalent; TSAT: Transferrin saturation

\section{Acknowledgements}

The authors thank the medical staff who supported this study in the Kohsaikai Bunkojin Clinic and Kohsaikai Kamioooka Jinsei Clinic.

Funding

There was no funding.

\section{Availability of data and materials}

The datasets analyzed during the present study are available from the corresponding author on reasonable request.

\section{Authors' contributions}

TK was involved in the study design, study procedure implementation, data collection, and article writing of the manuscript. TK, TF, and YT contributed to the study design, data analysis, and article writing of the manuscript. EU and MK contributed to the study design, data collection, and data analysis. SY, TO, KT, and $\mathrm{NH}$ reviewed the study design and interpretation of results. All authors read and approved the final manuscript.

\section{Competing interests}

The authors declare that they have no competing interests.

Consent for publication Not applicable. 


\section{Ethics approval and consent to participate}

The study was approved by the Ethical Committee of Yokohama City University (approval number B130110018) and was conducted under the Declaration of Helsinki. Written informed consent was obtained from all patients.

\section{Author details}

'Department of Medical Science and Cardiorenal Medicine, Yokohama City University Graduate School of Medicine and School of Medicine, Yokohama, Kanagawa, Japan. ${ }^{2}$ Kohsaikai Bunkojin Clinic, Yokohama, Kanagawa, Japan. ${ }^{3}$ Yokodai Central Clinic, Yokohama, Kanagawa, Japan. ${ }^{4}$ Center for Health Service Sciences, Yokohama National University, Yokohama, Kanagawa, Japan. ${ }^{5}$ Kohsaikai Yokohama Jinsei Hospital, Yokohama, Kanagawa, Japan. ${ }^{6}$ Kohsaikai Kamioooka Jinsei Clinic, Yokohama, Kanagawa, Japan.

Received: 10 November 2016 Accepted: 25 February 2017

Published online: 22 May 2017

\section{References}

1. Foley RN, Parfrey PS, Harnett JD, Kent GM, Murray DC, Barre PE. The impact of anemia on cardiomyopathy, morbidity and mortality in end-stage renal disease. Am J Kidney Dis. 1996;28:53-61.

2. Eschbach JW, Egrie JC, Downing MR, Browne JK, Adamson JW. Correction of the anemia of end stage renal disease with recombinant human erythropoietin. Results of a combined phase I and II clinical trial. N Engl J Med. 1987:316:73-8.

3. López-Gómez JM, Portolés JM, Aljama P. Factors that condition the response to erythropoietin in patients on hemodialysis and their relation to mortality. Kidney Int Suppl. 2008;111:S75-81.

4. Fujikawa T, Ikeda Y, Fukuhara S, Akiba T, Akizawa T, Kurokawa K, Saito A. Time-dependent resistance to erythropoiesis-stimulating agent and mortality in hemodialysis patients in the Japan Dialysis Outcomes and Practice Patterns Study. Nephron Clin Pract. 2012;122(1-2):24-32.

5. Richardson D. Clinical factors influencing sensitivity and response to epoetin. Nephrol Dial Transplant. 2002;17(Suppl):53-9.

6. Drüeke T. Hyporesponsiveness to recombinant human erythropoietin. Nephrol Dial Transplant. 2001:16:25-8.

7. Kidney Disease: Improving Global Outcomes (KDIGO) Anemia Work Group. KDIGO clinical practice guideline for anemia in chronic kidney disease. Kidney Int. 2012;2:279-335.

8. Locatelli F, Bárány P, Covic A, De Francisco A, Del Vecchio L, Goldsmith D, Hörl W, London G, Vanholder R, Van Biesen W, ERA-EDTA ERBP Advisory Board. Kidney Disease: Improving Global Outcomes guidelines on anaemia management in chronic kidney disease: a European Renal Best Practice position statement. Nephrol Dial Transplant. 2013;28(6):1346-59.

9. Tsubakihara Y, Nishi S, Akiba T, Hirakata H, Iseki K, Kubota M, Kuriyama S, Komatsu Y, Suzuki M, Nakai S, Hattori M, Babazono T, Hiramatsu M, Yamamoto H, Bessho M, Akizawa T. 2008 Japanese Society for Dialysis Therapy: guidelines for renal anemia in chronic kidney disease. Ther Apher Dial. 2010;14(3):240-75.

10. Brewster UC. Intravenous iron therapy in end-stage renal disease. Semin Dial. 2006;19(4):285-90

11. Kalantar-Zadeh K, Regidor DL, McAllister CJ, Michael B, Warnock DG. Timedependent associations between iron and mortality in hemodialysis patients. J Am Soc Nephrol. 2005;16(10):3070-80.

12. Major A, Mathez-Loic F, Rohling R, Gautschi K, Brugnara C. The effect of intravenous iron on the reticulocyte response to recombinant human erythropoietin. Br J Haematol. 1997;98:292-4.

13. Kakimoto-Shino M, Toya Y, Kuji T, Fujikawa T, Umemura S. Changes in hepcidin and reticulocyte hemoglobin equivalent levels in response to continuous erythropoietin receptor activator administration in hemodialysis patients: a randomized study. Ther Apher Dial. 2014;18(5):421-6.

14. Kuji T, Toya Y, Fujikawa T, Kakimoto-Shino M, Nishihara M, Shibata K, Tamura K, Hirawa N, Satta H, Kawata S, Kouguchi N, Umemura S. Acceleration of iron utilization after intravenous iron administration during activated erythropoiesis in hemodialysis patients: a randomized study. Ther Apher Dial. 2015;19(2):131-7.

15. Thomas L, Franck S, Messinger $M$, Linssen J, Thome $M$, Thomas $C$. Reticulocyte hemoglobin measurement-comparison of two methods in the diagnosis of iron-restricted erythropoiesis. Clin Chem Lab Med. 2005;43: 1193-202.
16. Fishbane S, Galgano C, Langley Jr RC, Canfield W, Maesaka JK. Reticulocyte hemoglobin content in the evaluation of iron status of hemodialysis patients. Kidney Int. 1997;52:217-22.

17. Goodnough LT, Skikne B, Brugnara C. Erythropoietin, iron, and erythropoiesis. Blood. 2000;96(3):823-33.

18. Besarab A, Kaiser JW. Frinak S A study of parenteral iron regimens in hemodialysis patients. Am J Kidney Dis. 1999;34(1):21-8.

19. Pai $A B$, Conner T, McQuade CR, Olp J, Hicks P. Non-transferrin bound iron, cytokine activation and intracellular reactive oxygen species generation in hemodialysis patients receiving intravenous iron dextran or iron sucrose. Biometals. 2011:24(4):603-13.

20. Nakanishi T, Kuragano T, Nanami M, Otaki Y, Nonoguchi H, Hasuike Y. Importance of ferritin for optimizing anemia therapy in chronic kidney disease. Am J Nephrol. 2010;32:439-46.

21. Locatelli F, Aljama P, Bárány P, Canaud B, Carrera F, Eckardt KU, Hörl WH, Macdougal IC, Macleod A, Wiecek A, Cameron S. European Best Practice Guidelines Working Group. Revised European best practice guidelines for the management of anaemia in patients with chronic renal failure. Nephrol Dial Transplant. 2004;19(Suppl 2):ii1-47.

22. Ghoti H, Rachmilewitz EA, Simon-Lopez R, Gaber R, Katzir Z, Konen E, Kushnir T, Girelli D, Campostrini N, Fibach E, Goitein O. Evidence for tissue iron overload in long-term hemodialysis patients and the impact of withdrawing parenteral iron. Eur J Haematol. 2012;89(1):87-93.

23. Swinkels DW, Wetzels JF. Hepcidin: a new tool in the management of anaemia in patients with chronic kidney disease? Nephrol Dial Transplant. 2008;23(8):2450-3.

\section{Submit your next manuscript to BioMed Central and we will help you at every step:}

- We accept pre-submission inquiries

- Our selector tool helps you to find the most relevant journal

- We provide round the clock customer support

- Convenient online submission

- Thorough peer review

- Inclusion in PubMed and all major indexing services

- Maximum visibility for your research

Submit your manuscript at www.biomedcentral.com/submit
) Biomed Central 